\title{
A DENGUE NOS LIVROS DIDÁTICOS DE CIÊNCIAS E BIOLOGIA INDICADOS PELO PROGRAMA NACIONAL DO LIVRO DIDÁTICO
}

\author{
Dengue in science and biology text books \\ indicated by the Didactic Book National Program
}

\author{
Sheila Soares de Assis $^{1}$. Denise Nacif Pimenta ${ }^{2}$. \\ Virgínia Torres Schall ${ }^{3}$
}

\begin{abstract}
Resumo: A dengue constitui um grave problema de saúde pública no Brasil. As Diretrizes Nacionais de Prevenção e Controle das Epidemias de Dengue preconizam que ações de educação em saúde associadas ao tema dengue sejam contempladas, no espaço escolar, na grade curricular das disciplinas. No ensino formal, o livro didático se caracteriza como um dos principais recursos para a prática docente e disseminação de conhecimentos científicos. Assim, analisou-se a temática da dengue nos livros didáticos de ciências e biologia, indicados pelos Programa Nacional do Livro Didático para o Ensino Médio (PNLEM/2009) e Programa Nacional do Livro Didático (PNLD/2008 e 2011), respectivamente. O tema esteve presente em quarenta livros didáticos dos 114 indicados pelo PNLD (2008 e 2011) e PNLEM (2009). Verificaram-se erros conceituais, emprego de ilustrações inadequadas e descontextualização sociocultural do conteúdo. Estes fatores limitam a utilização deste instrumento colaborativo para as ações desencadeadas no ambiente escolar com vistas ao controle da dengue.
\end{abstract}

Palavras-chave: Dengue. Educação em saúde. Livro didático. Ensino de Ciências. Ensino de Biologia.

\begin{abstract}
Dengue is a serious public health problem in Brazil. The National Guidelines for Prevention and Control of Dengue Epidemics recommend the presence of health education action in schools and inclusion of the topic in the curriculum of the disciplines. In formal education, the text book is characterized as one of the main tools for teaching and dissemination of scientific knowledge. Thus, we analyzed the theme of dengue in the text books of science and biology indicated by the Didactic Book National Program (PNLD/2008 and 2011) and the Didactic Book National Program for High School (PNLEM/2009), respectively. The theme was present in the forty text books of the 106 indicated by the PNLD (2008 and 2011) and PNLEM (2009). There were conceptual errors, the use of inappropriate illustrations and sociocultural decontextualization of the content. These factors limit the use of this collaborative resource for action to be carried out in the schools with the aim to control dengue.
\end{abstract}

Keywords: Dengue. Health education. Textbook. Science education. Biology teaching.

\footnotetext{
${ }^{1}$ Fundação Oswaldo Cruz (Fiocruz), Avenida Brasil, 4.365, Manguinhos, CEP 21045-900, Rio de Janeiro, RJ, Brasil. E-mail: sheila.assisbiouff@gmail.com

${ }^{2}$ Fundação Oswaldo Cruz (Fiocruz), Instituto de Comunicação e Informação Científica e Tecnológica em Saúde, Rio de Janeiro, RJ, Brasil.

${ }^{3}$ Fundação Oswaldo Cruz (Fiocruz), Centro de Pesquisas René Rachou, Laboratório de Educação em Saúde e Ambiente (LAESA), Belo Horizonte, MG, Brasil.
} 
Assis, S. S.; Pimenta, D. N.; Schall, V. T.

\section{Introdução}

A dengue é caracterizada como a principal arbovirose que acomete o ser humano. Estima-se que todos os anos ocorram cinquenta milhões de infecções em todo o mundo (WORLD HEALTH ORGANIZATION, 2009). No Brasil, o Ministério da Saúde reportou a ocorrência de 764.032 casos de dengue em 2011 (BRASIL, 2012). Dentre as medidas preconizadas para a prevenção e controle do agravo, incluem-se as ações de educação em saúde no espaço escolar. Essas ações devem levar em consideração os diferentes atores sociais envolvidos no processo, tais como: alunos, professores e demais membros que compõem a comunidade escolar (BRASIL, 2009).

Ainda neste sentido, em países que apresentam grande incidência de dengue, como o Brasil, a Organização Mundial da Saúde (OMS) recomenda a inclusão de tópicos referentes a seus vetores, transmissão, sinais e sintomas, e tratamento, no currículo escolar (WORLD HEALTH ORGANIZATION, 2009). As políticas educacionais, por sua vez, contemplam a abordagem do processo saúde/doença e seus condicionantes como um tema transversal. No entanto, na prática do contexto escolar, os temas relacionados à saúde recaem, majoritariamente, sobre a disciplina de ciências e biologia (MOHR, 2000; SCHALL, 2010). Os Parâmetros Curriculares Nacionais de Ciências Naturais (PCN) (BRASIL, 1998), voltados ao segundo segmento do Ensino Fundamental, apontam que os agravos relacionados à saúde, como a dengue, devem ser tratados de forma contextualizada com a vida dos alunos, privilegiando, assim, a construção de conhecimentos capazes de subsidiar, de forma autônoma, a adoção de práticas cotidianas que assegurem a preservação da saúde individual e coletiva. Para tal, é necessária uma abordagem que transcenda a mera descrição de processos biológicos (BRASIL, 1998). O indicativo é igualmente destacado nos Parâmetros Curriculares Nacionais para o Ensino Médio (PCNEM), relacionando, ainda, estes temas com o ambiente ${ }^{4}$ (BRASIL, 1999). Assim, as disciplinas de ciências e biologia, em conjunto com as demais disciplinas do currículo, configuram-se como espaços privilegiados para a formação de cidadãos críticos e aptos para colaborarem nas ações de prevenção e controle da dengue.

No espaço escolar, o livro didático (LD) $)^{5}$ corresponde a um importante instrumento capaz de auxiliar na prática docente. Caracteriza-se, ainda, como recurso mediador do conhecimento científico para os alunos, embasando, deste modo, a formação intelectual destes. Portanto, é imprescindível que seja mantido o comprometimento com a qualidade dos conteúdos presentes neste material, sobretudo com relação à atualização do conhecimento científico e à vinculação com a prática social dos professores e alunos.

\footnotetext{
${ }^{4} \mathrm{O}$ ambiente, como definido por Brügger (2004, p. 78), é aqui compreendido como uma totalidade que inclui os aspectos naturais e os resultantes das atividades humanas. Assim, o meio ambiente é percebido aqui como produto da interação de fatores biológicos, sociais, físicos, econômicos e culturais.

${ }^{5}$ Seguimos a definição atribuída por Oliveira, Guimarães e Bomény (1984) e Fracalanza e Megid Neto (2006), que caracterizam o livro didático como material impresso, estruturado, destinado e adequado para ser utilizado no processo de ensino e aprendizagem dentro do sistema formal de ensino.
} 
Freitag, Motta e Costa (1997) situam a criação do Programa Nacional do Livro Didático (PNLD), em 1985, como um avanço dentro das políticas voltadas ao LD, pois rompe com o paradigma de que este material seria somente um objeto didático descartável. Através do programa, propagaram-se obras duráveis, estimulando, assim, a melhora das condições físicas deste material. Nas políticas atuais que envolvem o LD, há um compromisso com a excelência dos conteúdos, sendo esta preocupação fortemente evidenciada por meio das avaliações sistemáticas promovidas pelo Ministério da Educação desde 1994 (HÖFFLING, 2006). A partir de 1996, as obras didáticas indicadas pelo Programa Nacional do Livro Didático (PNLD) passaram a ser divulgadas por meio do guia de livros didáticos, sendo publicado, em 1999, o primeiro guia de livros didáticos de ciências, destinado ao segundo segmento do Ensino Fundamental (LEÃO; MEGID NETO, 2006). O catálogo abriga as resenhas das coleções aprovadas pelo programa, bem como outros aspectos referentes à avaliação. O objetivo do material é auxiliar os docentes das escolas públicas do país na escolha da coleção didática a ser adotada. Dentro das políticas dos livros didáticos, as obras voltadas para o Ensino Médio adquiriram papel de destaque a partir da criação do Programa Nacional do Livro para o Ensino Médio (PNLEM), em 2003, por meio da Resolução n 38 do Fundo Nacional para Desenvolvimento da Educação (FNDE) (BRASIL, 2003). Esta resolução visou assegurar a qualidade e a universalização do LD para este segmento de ensino (BRASIL, 2003). As obras didáticas de biologia foram acolhidas pelo programa somente a partir de 2006. A distribuição das coleções aprovadas pelo programa para escolas públicas ocorreu no ano seguinte (BRASIL, 2007a). Atualmente, no PNLD 2012, o PNLEM foi incorporado ao Programa Nacional do Livro Didático (PNLD) (BRASIL, Ministério da Educação, 2011).

Estudos como os de Mohr (2000), Megid Neto e Fracalanza (2003), Almeida, Silva e Brito (2008), Santos e El-Hani (2009), Batista, Cunha e Cândido (2010) reportam que, mesmo com os diversos esforços empregados pelo MEC para assegurar a qualidade das obras didáticas, em especial as de ciências e biologia, que chegam aos alunos do Ensino Básico, estas ainda apresentam inadequações no que se refere ao seu conteúdo e ilustrações. É necessário que os livros didáticos de ciências, bem como os de biologia, sejam empregados não somente como fonte de informações, mas que este material seja corresponsável pelo desenvolvimento de competências necessárias para a vida, tais como: a observação, a crítica, a análise, a reflexão e, especialmente, a propriedade de estabelecer relações entre os conteúdos científicos apresentados e o cotidiano vivenciado pelo discente (SILVA; SOUZA; DUARTE, 2009).

Concordamos com o prefácio de Ezequiel T. da Silva (MOLINA, 1988, p.11) quando afirma que "o livro didático não é um fim em si mesmo, mas um complemento ao trabalho global dos professores e alunos". A importância do LD não se restringe aos seus aspectos pedagógicos e às suas possíveis influências na aprendizagem e no desempenho do aluno. Destaca-se, segundo Oliveira, Guimarães e Bomény (1984, p. 11), que:

[...] o livro didático também é importante por seu aspecto político e cultural, na medida em que reproduz e representa os valores da sociedade em relação à sua visão de ciência, da história, da interpretação dos fatos e do próprio processo de construção do conhecimento. 
Assis, S. S.; Pimenta, D. N.; Schall, V. T.

Os autores prosseguem enfatizando que os livros didáticos imprimem "[...] modos de conceber e retransmitir a ciência, revelando padrões que terão profunda influência na formação posterior do indivíduo" (OLIVEIRA; GUIMARÃES; BOMÉNY, 1984, p. 16). Deste modo, o presente trabalho objetiva analisar a qualidade e coerência científica da temática da dengue presente nos livros de ciências e biologia indicados pelo PNLD 2008 e 2011 e PNLEM 2009, respectivamente. Almeja-se refletir sobre o potencial de cooperação destas obras para a construção de conhecimentos e formação cidadã nas ações de prevenção e controle da dengue. Analisar como a dengue é representada nos LD torna-se de fundamental importância, pois nos auxilia a pensar criticamente sobre um dos mais valiosos instrumentos pedagógicos utilizados na sala de aula.

\section{Material e métodos}

Seleção dos livros didáticos

Realizou-se um levantamento das coleções de ciências indicadas nos catálogos referentes ao PNLD 2008 e 2011, e de biologia apresentadas no guia do PNLEM 2009 (BRASIL, 2007b, 2008, 2010), que totalizaram 114 exemplares para essas disciplinas no período. O catálogo do PNLD 2008 apresentou 13 coleções didáticas (52 livros) e, no guia de livros didáticos do PNLD 2011, foram descritas 11 coleções (44 livros). Todos os exemplares didáticos foram examinados, sendo a temática identificada em somente 14 obras didáticas do PNLD 2008 (Quadro 1) e em 16 obras vinculadas ao PNLD 2011 (Quadro 2). Desta forma, no total, trinta livros didáticos de ciências foram analisados.

Já com relação aos livros de biologia, verificou-se a abordagem do tema dengue em dez exemplares didáticos dos 18 descritos no catálogo (Quadro 3).

\section{Critérios e procedimentos de análise}

Para a execução das análises, foram consideradas citações, textos e ilustrações referentes à dengue ou aos seus vetores presentes nos capítulos das obras didáticas. Textos informativos e imagens, quando presentes em blocos de exercícios, também foram considerados.

Os tópicos que nortearam a análise foram adaptados a partir dos itens propostos por Almeida, Silva e Brito (2008), Batista, Cunha e Cândido (2010), Ferreira e Soares (2008), Luz et al. (2003), Mohr (2000), Santos et al. (2007) e Vasconcelos e Souto (2003). Estes foram dispostos em um formulário padrão e subdivididos em quatro grandes blocos de análise, a saber: 1) estrutura e formatação; 2) conteúdo; 3) linguagem; e 4) ilustrações. Esses blocos foram subdivididos contendo os tópicos de análise apresentados no Quadro 4. 
A dengue nos livros didáticos ...

Quadro 1. Livros didáticos analisados do PNLD 2008

\begin{tabular}{|c|c|c|c|c|c|}
\hline Livro & Autores & Título do livro & $\begin{array}{l}\text { Série } \\
\text { Ano }\end{array}$ & $\begin{array}{l}\text { Editora } \\
\text { Cidade }\end{array}$ & Ano \\
\hline 1 & Carlos Barros e Wilson Paulino & Ciências - seres vivos & $\begin{array}{l}6^{\mathrm{a}} \text { série } \\
7^{\circ} \text { ano }\end{array}$ & $\begin{array}{c}\text { Ática } \\
\text { São Paulo }\end{array}$ & 2006 \\
\hline 2 & Fernando Gewandsznajder & Ciências - o planeta Terra & $\begin{array}{l}5^{\mathrm{a}} \text { série } \\
6^{0} \text { ano }\end{array}$ & $\begin{array}{c}\text { Ática } \\
\text { São Paulo }\end{array}$ & 2006 \\
\hline 3 & Fernando Gewandsznajder & Ciências - a vida na Terra & $\begin{array}{l}6^{\mathrm{a}} \text { série } \\
7^{0} \text { ano }\end{array}$ & $\begin{array}{c}\text { Ática } \\
\text { São Paulo }\end{array}$ & 2006 \\
\hline 4 & Nélio Bizzo e Marcelo Jordão & Ciências BJ & $\begin{array}{l}6^{\mathrm{a}} \text { série } \\
7^{0} \text { ano }\end{array}$ & $\begin{array}{l}\text { Editora do } \\
\text { Brasil } \\
\text { São Paulo }\end{array}$ & 2006 \\
\hline 5 & $\begin{array}{l}\text { Demétrio Gowdak e Eduardo } \\
\text { Martins }\end{array}$ & Ciências - novo pensar & $\begin{array}{l}5^{\mathrm{a}} \text { série } \\
6^{\circ} \text { ano }\end{array}$ & $\begin{array}{c}\text { FTD } \\
\text { São Paulo }\end{array}$ & 2006 \\
\hline 6 & $\begin{array}{l}\text { Demétrio Gowdak e Eduardo } \\
\text { Martins }\end{array}$ & Ciências - novo pensar & $\begin{array}{l}7^{\mathrm{a}} \text { série } \\
8^{\circ} \text { ano }\end{array}$ & $\begin{array}{c}\text { FTD } \\
\text { São Paulo }\end{array}$ & 2006 \\
\hline 7 & José Trivellato et al. & Ciências: natureza \& cotidiano & $\begin{array}{l}6^{\mathrm{a}} \text { série } \\
7^{0} \text { ano }\end{array}$ & $\begin{array}{c}\text { FTD } \\
\text { São Paulo }\end{array}$ & 2006 \\
\hline 8 & $\begin{array}{l}\text { Ana Paula Hermanson e Mônica } \\
\text { Jakievicius }\end{array}$ & $\begin{array}{l}\text { Investigando a natureza: ciências } \\
\text { para o Ensino Fundamental }\end{array}$ & $\begin{array}{l}8^{\mathrm{a}} \text { série } \\
9^{\circ} \text { ano }\end{array}$ & $\begin{array}{c}\text { IBEP } \\
\text { São Paulo }\end{array}$ & 2006 \\
\hline 9 & Eduardo Leite do Canto & $\begin{array}{l}\text { Ciências naturais: aprendendo } \\
\text { com o cotidiano }\end{array}$ & $\begin{array}{l}5^{\mathrm{a}} \text { série } \\
6^{0} \text { ano }\end{array}$ & $\begin{array}{l}\text { Moderna } \\
\text { São Paulo }\end{array}$ & 2004 \\
\hline 10 & Eduardo Leite do Canto & $\begin{array}{l}\text { Ciências naturais: aprendendo } \\
\text { com o cotidiano }\end{array}$ & $\begin{array}{l}6^{\mathrm{a}} \text { série } \\
7^{0} \text { ano }\end{array}$ & $\begin{array}{l}\text { Moderna } \\
\text { São Paulo }\end{array}$ & 2004 \\
\hline 11 & Obra coletiva & Projeto Araribá: ciências & $\begin{array}{l}6^{\mathrm{a}} \text { série } \\
7^{0} \text { ano }\end{array}$ & $\begin{array}{l}\text { Moderna } \\
\text { São Paulo }\end{array}$ & 2006 \\
\hline 12 & Selma Braga et al. & Construindo consciências & $\begin{array}{l}5^{\mathrm{a}} \text { série } \\
6^{\circ} \text { ano }\end{array}$ & $\begin{array}{l}\text { Scipione } \\
\text { São Paulo }\end{array}$ & 2006 \\
\hline 13 & Alice Costa & Ciências e interação & $\begin{array}{l}6^{\mathrm{a}} \text { série } \\
7^{0} \text { ano }\end{array}$ & $\begin{array}{l}\text { Positivo } \\
\text { Curitiba }\end{array}$ & 2006 \\
\hline 14 & Silvia Bortolozzo e Suzana Maluhy & Link da ciência & $\begin{array}{l}6^{\mathrm{a}} \text { série } \\
7^{0} \text { ano }\end{array}$ & $\begin{array}{c}\text { Escala } \\
\text { Educacional } \\
\text { São Paulo }\end{array}$ & 2005 \\
\hline
\end{tabular}

Fonte: Brasil (2007b). 
Assis, S. S.; Pimenta, D. N.; Schall, V. T.

Quadro 2. Livros didáticos de ciências analisados indicados no PNLD 2011

\begin{tabular}{|c|c|c|c|c|c|}
\hline Livro & Autores & Título do livro & $\begin{array}{l}\text { Série } \\
\text { Ano }\end{array}$ & $\begin{array}{l}\text { Editora } \\
\text { Cidade }\end{array}$ & Ano \\
\hline 1 & $\begin{array}{l}\text { Maria Figueiredo e Cecília } \\
\text { Condeixa }\end{array}$ & Ciências: atitude e conhecimento & $\begin{array}{l}5^{\mathrm{a}} \text { série } \\
6^{\circ} \text { ano }\end{array}$ & $\begin{array}{c}\text { FTD } \\
\text { São Paulo }\end{array}$ & 2009 \\
\hline II & $\begin{array}{l}\text { Maria Figueiredo e Cecília } \\
\text { Condeixa }\end{array}$ & Ciências: atitude e conhecimento & $\begin{array}{l}6^{a} \text { série } \\
7^{0} \text { ano }\end{array}$ & $\begin{array}{c}\text { FTD } \\
\text { São Paulo }\end{array}$ & 2009 \\
\hline III & $\begin{array}{l}\text { Maria Figueiredo e Cecília } \\
\text { Condeixa }\end{array}$ & Ciências: atitude e conhecimento & $\begin{array}{l}8^{\mathrm{a}} \text { série } \\
9^{\circ} \text { ano }\end{array}$ & $\begin{array}{c}\text { FTD } \\
\text { São Paulo }\end{array}$ & 2009 \\
\hline IV & José Trivellato Júnior et al. & Ciências, natureza \& cotidiano & $\begin{array}{l}6^{\mathrm{a}} \text { série } \\
7^{0} \text { ano }\end{array}$ & $\begin{array}{c}\text { FTD } \\
\text { São Paulo }\end{array}$ & 2009 \\
\hline V & Eduardo Leite do Canto & $\begin{array}{l}\text { Ciências naturais: aprendendo } \\
\text { com o cotidiano }\end{array}$ & $\begin{array}{l}5^{\mathrm{a}} \text { série } \\
6^{\circ} \text { ano }\end{array}$ & $\begin{array}{l}\text { Moderna } \\
\text { São Paulo }\end{array}$ & 2009 \\
\hline VI & Eduardo Leite do Canto & $\begin{array}{l}\text { Ciências naturais: aprendendo } \\
\text { com o cotidiano }\end{array}$ & $\begin{array}{l}6^{a} \text { série } \\
7^{0} \text { ano }\end{array}$ & $\begin{array}{l}\text { Moderna } \\
\text { São Paulo }\end{array}$ & 2009 \\
\hline VII & $\begin{array}{l}\text { Olga Santana; Aníbal Fonseca e } \\
\text { Erika Mozena }\end{array}$ & Ciências naturais & $\begin{array}{l}5^{\mathrm{a}} \text { série } \\
6^{\circ} \text { ano }\end{array}$ & $\begin{array}{l}\text { Saraiva } \\
\text { São Paulo }\end{array}$ & 2009 \\
\hline VIII & Selma Braga et al. & Construindo consciências & $\begin{array}{l}8^{\mathrm{a}} \text { série } \\
9^{\circ} \text { ano }\end{array}$ & $\begin{array}{l}\text { Scipione } \\
\text { São Paulo }\end{array}$ & 2009 \\
\hline IX & Selma Braga et al. & Construindo consciências & $\begin{array}{l}5^{\mathrm{a}} \text { série } \\
6^{\circ} \text { ano }\end{array}$ & $\begin{array}{l}\text { Scipione } \\
\text { São Paulo }\end{array}$ & 2009 \\
\hline$X$ & Fernando Gewandsznajder & Ciências - o planeta Terra & $\begin{array}{l}5^{\mathrm{a}} \text { série } \\
6^{\circ} \text { ano }\end{array}$ & $\begin{array}{c}\text { Ática } \\
\text { São Paulo }\end{array}$ & 2009 \\
\hline $\mathrm{XI}$ & Fernando Gewandsznajder & Ciências - a vida na Terra & $\begin{array}{l}6^{\mathrm{a}} \text { série } \\
7^{0} \text { ano }\end{array}$ & $\begin{array}{c}\text { Ática } \\
\text { São Paulo }\end{array}$ & 2009 \\
\hline XII & Carlos Barros e Wilson Paulino & Ciências - os seres vivos & $\begin{array}{l}6^{\mathrm{a}} \text { série } \\
7^{0} \text { ano }\end{array}$ & $\begin{array}{c}\text { Ática } \\
\text { São Paulo }\end{array}$ & 2009 \\
\hline XIII & Ana Maria Pereira et al. & Perspectiva ciências & $\begin{array}{l}6^{\mathrm{a}} \text { série } \\
7^{0} \text { ano }\end{array}$ & $\begin{array}{l}\text { Editora do } \\
\text { Brasil } \\
\text { São Paulo }\end{array}$ & 2009 \\
\hline XIV & Nélio Bizzo e Marcelo Jordão & Ciências BJ & $\begin{array}{l}6^{a} \text { série } \\
7^{0} \text { ano }\end{array}$ & $\begin{array}{c}\text { Editora do } \\
\text { Brasil } \\
\text { São Paulo }\end{array}$ & 2009 \\
\hline$X V$ & $\begin{array}{l}\text { Elisangela Angelo; Karina Silva; } \\
\text { Leonel Favalli }\end{array}$ & Projeto Radix: ciências & $\begin{array}{l}5^{\mathrm{a}} \text { série } \\
6^{\circ} \text { ano }\end{array}$ & $\begin{array}{l}\text { Scipione } \\
\text { São Paulo }\end{array}$ & 2009 \\
\hline $\mathrm{XVI}$ & $\begin{array}{l}\text { Elisangela Angelo; Karina Silva; } \\
\text { Leonel Favalli }\end{array}$ & Projeto Radix: ciências & $\begin{array}{l}6^{a} \text { série } \\
7^{0} \text { ano }\end{array}$ & $\begin{array}{l}\text { Scipione } \\
\text { São Paulo }\end{array}$ & 2009 \\
\hline
\end{tabular}

Fonte: Brasil (2010). 
Quadro 3. Livros didáticos de biologia analisados indicados pelo PNLEM 2009

\begin{tabular}{|c|c|c|c|c|c|}
\hline Livro & Autores & Título do livro & $\begin{array}{l}\text { Série } \\
\text { Ano }\end{array}$ & $\begin{array}{l}\text { Editora } \\
\text { Cidade }\end{array}$ & Ano \\
\hline A & $\begin{array}{l}\text { Sergio Linhares e Fernando } \\
\text { Gewandsznajder }\end{array}$ & Biologia: volume único & $\begin{array}{l}\text { Ensino } \\
\text { Médio }\end{array}$ & $\begin{array}{c}\text { Ática } \\
\text { São Paulo }\end{array}$ & 2005 \\
\hline B & $\begin{array}{l}\text { José Arnaldo Favaretto e Clarinda } \\
\text { Mercadante }\end{array}$ & Biologia: volume único & $\begin{array}{l}\text { Ensino } \\
\text { Médio }\end{array}$ & $\begin{array}{l}\text { Moderna } \\
\text { São Paulo }\end{array}$ & 2005 \\
\hline $\mathrm{C}$ & J. Laurence & Biologia: volume único & $\begin{array}{l}\text { Ensino } \\
\text { Médio }\end{array}$ & $\begin{array}{l}\text { Nova geração } \\
\text { São Paulo }\end{array}$ & 2005 \\
\hline $\mathrm{D}$ & César Silva Júnior e Sezar Sasson & $\begin{array}{l}\text { Biologia: as características da } \\
\text { vida, biologia celular, vírus - entre } \\
\text { moléculas e células, a origem da } \\
\text { vida e histologia animal }\end{array}$ & $1^{\mathrm{a}}$ série & $\begin{array}{l}\text { Saraiva } \\
\text { São Paulo }\end{array}$ & 2005 \\
\hline$E$ & César Silva Júnior e Sezar Sasson & $\begin{array}{l}\text { Biologia - seres vivos: estrutura e } \\
\text { função }\end{array}$ & $2^{\mathrm{a}}$ série & $\begin{array}{l}\text { Saraiva } \\
\text { São Paulo }\end{array}$ & 2005 \\
\hline $\mathrm{F}$ & José Amabis e Gilberto Martho & Biologia dos organismos & $2^{\mathrm{a}}$ série & $\begin{array}{l}\text { Moderna } \\
\text { São Paulo }\end{array}$ & 2004 \\
\hline G & Wilson Paulino & Biologia: seres vivos e fisiologia & $2^{\mathrm{a}}$ série & $\begin{array}{c}\text { Ática } \\
\text { São Paulo }\end{array}$ & 2005 \\
\hline $\mathrm{H}$ & Sônia Lopes e Sergio Rosso & Biologia: volume único & $\begin{array}{l}\text { Ensino } \\
\text { Médio }\end{array}$ & $\begin{array}{l}\text { Saraiva } \\
\text { São Paulo }\end{array}$ & 2005 \\
\hline 1 & Oswaldo Frota-Pessoa & Biologia & $2^{\mathrm{a}}$ série & $\begin{array}{l}\text { Scipione } \\
\text { São Paulo }\end{array}$ & 2005 \\
\hline $\mathrm{J}$ & $\begin{array}{l}\text { Augusto Adolfo; Marcos Crozetta e } \\
\text { Samuel Lago }\end{array}$ & Biologia: volume único & $\begin{array}{l}\text { Ensino } \\
\text { Médio }\end{array}$ & $\begin{array}{c}\text { IBEP } \\
\text { São Paulo }\end{array}$ & 2005 \\
\hline
\end{tabular}

Fonte: Brasil (2008).

O modelo de coleta de dados contemplado no estudo permite analisar o que é efetivamente emitido em relação à dengue nos livros didáticos, ou seja, privilegia-se a reflexão sobre o que é oferecido aos alunos e professores das escolas públicas do país para a compreensão do agravo. Portanto, este trabalho não teve a intenção de verificar o que foi compreendido pelo público que faz uso dos livros didáticos ou qual mensagem os autores pretendiam transmitir sobre o tema. Desta forma, o foco da análise foi o conteúdo e imagens sobre a dengue presentes nos livros didáticos. 
Assis, S. S.; Pimenta, D. N.; Schall, V. T.

Quadro 4. Categorias e tópicos de análise

\begin{tabular}{|l|l|}
\hline \multicolumn{1}{|c|}{ Categorias } & \multicolumn{1}{c|}{ Tópicos } \\
\hline 1. Estrutura e formatação & $\begin{array}{l}\text { (a) tamanho do texto (número de páginas); (b) indicação de outros autores ou } \\
\text { colaboradores; (c) localização do tema no exemplar (texto, exercícios, texto } \\
\text { complementar, anexos, dentre outros); (d) se a fonte utilizada favorece a } \\
\text { leitura. }\end{array}$ \\
\hline 2. Conteúdo & $\begin{array}{l}\text { (a) necessidade de pré-requisito para compreensão; (b) correção científica; (c) } \\
\text { adequação à série do público-alvo; (d) presença de explicação para termos } \\
\text { científicos e/ou desconhecidos; (e) contextualização em relação ao público- } \\
\text { alvo; (f) falta/excesso de definições; (g) referências bibliográficas e conceitos } \\
\text { atuais; (h) tópicos abordados; (i) adoção de algum enfoque quanto à } \\
\text { abordagem do tema; (j) quais medidas de prevenção/controle e tratamento } \\
\text { foram informadas/indicadas; (k) referência ao ambiente; (I) contextualização } \\
\text { com a prática social do aluno e com capítulo ao qual está inserido. }\end{array}$ \\
\hline 3. Linguagem & $\begin{array}{l}\text { (a) clareza e objetividade; (b) linguagem compreensível e adequada; (c) } \\
\text { presença de ideias preconceituosas ou estereotipadas. }\end{array}$ \\
\hline 4. Ilustrações & $\begin{array}{l}\text { (a) pertinência ou redundância em relação ao texto; (b) presença ou não de } \\
\text { escala; (c) presença ou não de autoria; (d) apresentação atraente; (e) } \\
\text { apresentação organizada; (f) qualidade satisfatória; (g) quantidade pertinente, } \\
\text { e (h) presença de legenda. }\end{array}$ \\
\hline
\end{tabular}

Fonte: Adaptado a partir de Almeida, Silva e Brito (2008), Batista, Cunha e Cândido (2010), Ferreira e Soares (2008), Luz et al. (2003), Mohr (2000), Santos et al. (2007) e Vasconcelos e Souto (2003).

\section{Resultados e discussão}

\section{Estrutura e Formatação}

Com relação à estrutura e formatação, em $53 \%(n=21)$ das obras de ciências e biologia analisadas, o tema da dengue esteve vinculado aos capítulos destinados à abordagem dos vírus. Nestes exemplares, o tema é tratado de forma sintética e com o caráter de exemplificação das doenças vinculadas aos vírus. No entanto, como apontam Batista, Cunha e Candido (2010), em relação às viroses, a dengue apresenta alta relevância para a população brasileira, exigindo que o conteúdo seja abordado de forma mais aprofundada, não apenas de forma superficial restringindo-se somente aos processos biológicos. $\mathrm{O}$ tema ainda esteve presente em capítulos destinados a: abordagem de ciclo de vida de animais e plantas; doenças que apresentam sua transmissão associada à água; agravos à saúde; relações ecológicas; artrópodes; problemas do ambiente urbano, e, ainda, em um bloco destinado ao Reino Protista (livro 4). Neste exemplar, o assunto apresenta-se de forma bastante descontextualizada do restante do tema abordado no capítulo, pois não há uma sequência lógica com outros tópicos abordados e a aprendizagem não é favorecida. Nos exemplares III e VIII, o conteúdo sobre a dengue é alocado em capítulos cujo enfoque é a saúde. Este tipo de abordagem é bastante interessante, pois diferentes condicionantes, referentes aos agravos de saúde, são mencionados e relacionados com a incidência da doença.

Quanto à extensão do tema, Carlini-Cotrim e Rosemberg (1991) destacam que, através do espaço destinado a um determinado tópico em uma obra didática, é possível verificar a 
importância atribuída pelo autor ao assunto. Em todas as obras analisadas, o espaço ocupado por questões referentes à dengue correspondeu, no máximo, a meia página. No entanto, no exemplar 11, o tópico da dengue obteve maior destaque em comparação com as demais obras, ocupando o espaço equivalente ao de duas páginas.

A menção ou citação de outros autores e outros colaboradores esteve presente quando foram reproduzidos trechos de reportagens ou dados epidemiológicos. Foi verificado, também, que somente quatro obras $(6 ; 5 ; 9$; XIII) indicam alguma fonte secundária para aprofundamento das questões levantadas ou para uma consulta posterior; estas indicações são importantes em uma obra com fins didáticos, pois auxiliam na indicação de textos de qualidade que aprofundem o tema. O livro didático como um recurso auxiliar à prática docente não é obrigado a abordar todos os conteúdos recomendados no currículo, assim, a indicação de outras fontes para consulta suplementar é oportuna para os alunos e professores.

\section{Conteúdo}

\section{Concepções gerais sobre a doença}

Ao abordarem a dengue, $55 \%(n=22)$ do total de livros analisados $(n=40)$ privilegiaram uma abordagem voltada estritamente à sintomatologia da doença. Dentre os livros de ciências e biologia apreciados, apenas $35 \%(n=14)$ reportaram a distinção em relação às duas formas clínicas, a clássica e a dengue hemorrágica. Este fato é preocupante, tendo em vista que a descrição da sintomatologia das doenças, bem como a configuração de seu quadro clínico nas aulas de ciências é extremante relevante para que os indivíduos não só conheçam os mecanismos patológicos, mas possam atuar sobre eles de modo a evitar maiores complicações quanto à doença (BRASIL, 1998; WORLD HEALTH ORGANIZATION, 2009).

Foram encontradas inadequações e incorreções quanto aos sintomas da dengue, como, por exemplo, no exemplar V, do PNLD 2011, o autor enfatiza de forma incorreta que a primeira infecção pelo vírus da dengue não é fatal. As manifestações da doença estão intimamente relacionadas com as condições e características físicas de cada indivíduo (WORLD HEALTH ORGANIZATION, 2009). Assim, é possível que o indivíduo, na primeira infecção, apresente sintomas graves (WORLD HEALTH ORGANIZATION, 2009). O apontamento da dengue como uma enfermidade benigna pode induzir a comunidade escolar a não procurar atendimento médico em casos suspeitos, e, ainda, estimular a busca por automedicação.

Nas obras E e I indicadas pelo PNLEM 2009, a sintomatologia da dengue é atribuída como semelhante à da febre amarela, não sendo destacada nenhuma peculiaridade entre uma e outra. A abordagem é inadequada, uma vez que a dengue e a febre amarela são retratadas sem que haja distinção entre os agravos, fato que pode gerar confusão quanto aos aspectos a elas relacionados, especialmente em regiões onde as doenças coexistem. A descrição dos sintomas contribui para o autocuidado em saúde e iniciativa de busca de tratamento, ao permitir distinguir os sintomas relacionados às patologias.

A descrição da doença nas coleções didáticas, de modo geral, esteve restrita à abordagem biomédica, por meio da indicação prescritiva dos sintomas. Como aponta Herzlich (2004), independentemente do fenômeno biológico, a doença constitui um fenômeno social e deve ser 
Assis, S. S.; Pimenta, D. N.; Schall, V. T.

pensada num arcabouço teórico mais amplo. No entanto, em nenhum dos livros analisados foram considerados outros domínios relacionados ao processo saúde/doença, contrariando, assim, as recomendações, presentes no PCN e PCNEM, de que os agravos devem transpor os aspectos biológicos (BRASIL, 1998, 1999).

\section{Concepções sobre a epidemiologia da doença}

Em sua maioria, os aspectos históricos da dengue estiveram ausentes nas obras contempladas pelo PNLD 2008 e pelo PNLEM 2009, sendo retratados apenas em três (27\%) exemplares do PNLD 2011 (III; IV e VIII). No entanto, no exemplar VIII é destacado, de forma incorreta, que "no Brasil, a dengue é uma doença introduzida há pouco mais de 20 anos" (BRAGA et al., 2009b, p. 169). Barreto e Teixeira (2008) reportam que relatos de epidemias de dengue estão presentes no Brasil desde 1846. Devido a numerosos esforços empregados entre os anos de 1920 e 1950, a dengue foi considerada erradicada por mais de trinta anos, sendo verificada a sua reintrodução no país na década de 1980 (BRASIL, 2009). É por este motivo que a doença é denominada de doença reemergente por alguns autores. O relato histórico de doenças no ensino de ciências, bem como nos livros didáticos desta disciplina, é importante, uma vez que contribui para a compreensão dos agravos em uma perspectiva mais ampla, pois o processo saúde/doença é fortemente influenciado por um vasto conjunto de fatores que extrapolam os aspectos naturais, também condicionado por fatores sociais e históricos (BRASIL, 1998). Para que o conteúdo de ciências e biologia se faça realmente contextualizado no livro didático, não é oportuno que sejam negligenciados fatores relacionados às questões históricas, socioeconômicas e culturais da população à qual as obras são destinadas (BARZANO, 2009). É preciso ponderar que a descrição histórica de doenças e os mecanismos preventivos a elas empregados proporcionam a reflexão quanto ao conjunto de regras sanitaristas comumente impostas nas ações que visam contenção de endemias (REIS, 2006). Assim, a exposição dos agravos à saúde em um recorte temporal nos livros didáticos oferece, ao seu público, a oportunidade de ponderar sobre os modelos verticalizados impostos em nossa sociedade para o controle de doenças como a dengue (ALBUQUERQUE, 2005).

Observou-se uma limitação espacial com relação ao tema nas obras analisadas que integram os Guias de Livros Didáticos do PNLD 2008 e 2011 e PNLEM 2009. Na maioria dos exemplares, a incidência da doença é atribuída apenas às metrópoles, ou seja, o agravo é percebido em um recorte espacial restringido, de modo que fatores sociais são excluídos ou não explicitados ao se mencionar a epidemiologia da doença. $O$ fato pode ser exemplificado através da generalização empregada no livro 9. Neste exemplar, o autor situa a dengue como sendo uma doença restrita às grandes cidades quando pontua "quais são os problemas mais sérios do nosso ambiente urbano?" (CANTO, 2004b, p. 123). Machado, Oliveira e SouzaSantos (2009) destacam a estreita ligação entre as atividades humanas que modificam os ambientes e ocasionam a vulnerabilidade das populações a agravos como a dengue. Assim, as práticas executadas no espaço, seja ele rural ou urbano, é que vão repercutir na proliferação do Aedes aegypti, e não necessariamente o espaço em si. É necessário pontuar ainda que o atual tráfego das populações consiste em um aspecto facilitador para a dispersão dos vetores, de modo que a doença não se limita somente às grandes cidades. Apesar de a dengue ser um problema majoritariamente de ambientes urbanos nas Américas e no Brasil, não se deve corre- 
lacionar o tema somente a estes territórios, pois a doença pode ocorrer, também, em ambientes rurais, como verificado em outros locais do mundo, tal como no Sudeste da Ásia (WORLD HEALTH ORGANIZATION, 2009). É importante considerar ainda que os livros didáticos acolhidos pelo PNLD e PNLEM possuem distribuição nacional, sendo estas obras amplamente disseminadas para comunidades escolares localizadas em ambiente rural e urbano. Assim, o material não deve privilegiar somente um grupo, mas, sim, considerar a heterogeneidade espacial do país.

Em relação às obras aprovadas pelo PNLD 2011, somente o exemplar VIII apresenta a temática da dengue em um contexto mais amplo que os fatores patológicos, estimulando alunos e professores a refletirem sobre a influência das variantes ambientais envolvidas no ciclo da doença. Os autores elencam alguns dos fatores que são condicionantes ao agravo. Assim, a dengue não é pensada apenas como produto da ação direta de um patógeno sobre o homem, mas como manifestação de múltiplos condicionantes capazes de gerar agravos à saúde humana.

Os dados epidemiológicos da dengue no território brasileiro foram retratados em 12,5\% ( $\mathrm{n}=5)$ dos exemplares analisados (9; 11; III; VIII e E). Todos os livros apresentam dados desatualizados. Ainda assim, a apresentação de tais informações pode instigar uma discussão sobre os fatores sociais envolvidos na variação da incidência da endemia em diferentes regiões do país e relevantes para a formação crítica dos estudantes.

\section{Concepções sobre a etiologia/vetor}

Verificaram-se equívocos referentes à reprodução do Aedes aegypti em 37,5\% (n=15) das obras analisadas. Nos livros 2, 3, 13, 9 e 11, II, X, XI e XII, A, F, G, H, I e J, enfatizou-se a realização da oviposição do Aedes aegypti em "água parada". Tal informação é incorreta, uma vez que o referido vetor realiza a sua reprodução na interface ar-água em ambientes úmidos e potencialmente inundáveis, diferente de outros membros da família Culicidae, como, por exemplo, o Culex sp, que realiza a postura de ovos efetivamente dentro da água (BRASIL, 2009). A descrição incorreta dos hábitos reprodutivos do principal vetor da dengue no Brasil pode acarretar em medidas ineficientes de contenção da reprodução do inseto no interior das residências. Somente nos livros 3, XII, XIII, F é mencionado o fato de a dengue possuir mais de um vetor. No entanto, a informação apresentada no exemplar 3 é desatualizada, pois afirma-se que o Aedes albopictus não é encontrado no Brasil. O primeiro registro do inseto no país data do ano de 1986. O vetor ainda não está associado a casos de dengue no Brasil, mas merece atenção já que é um potencial vetor da doença, sendo observada a ocorrência de epidemias associadas a ele em outras regiões do mundo (SANTOS, 2003).

Foi verificada inadequação quanto à linguagem empregada na obra 6 do PNLD 2008 com relação à transmissão da dengue. $\mathrm{Na}$ obra, a dengue é apenas citada no capítulo sobre ecologia, e o agravo é descrito em uma seção intitulada "Outras doenças causadas por vetores". O título do bloco no qual a dengue está descrita é impróprio, tendo em vista que a dengue, assim como outras patologias, não são causadas pelos vetores em si, mas, sim, por agentes patogênicos carreados por estes seres vivos (vetores) até o hospedeiro final. Para que a transmissão da dengue se processe, é necessária a presença do vetor. Ou seja, o vírus não é transmitido homem a homem. É oportuno citar que a inserção da dengue em capítulos onde 
Assis, S. S.; Pimenta, D. N.; Schall, V. T.

são alocadas múltiplas doenças infecciosas pode gerar confusão quanto ao agente etiológico e formas de transmissão de cada doença.

Nas coleções didáticas, em alguns momentos, são empregados termos ou conceitos, em relação ao vetor e ao agente etiológico, que podem acarretar uma falta de clareza para os leitores. $\mathrm{Na}$ abordagem realizada nos livros 12, IX, B, E e I, os autores descrevem o gênero Aedes como vetor da dengue. A informação aponta que os indivíduos pertencentes a este gênero são vetores da doença. Contudo, este fato não é verdadeiro. Nos exemplares 12 e IX, é proposta a participação dos alunos na busca por possíveis focos de vetores de doenças. Embora seja desejável a participação da população nas ações de controle de vetores envolvidos na transmissão das doenças, é necessário que isso se faça com prudência. Alguns locais, como terrenos baldios, podem oferecer riscos à saúde, sobretudo para crianças; assim, caberia um alerta, nos exemplares, a este respeito. Outro erro conceitual observado relaciona-se à etiologia da doença. Linhares e Gewandsznajder (2005) apresentam informações que, também, podem causar confusão de conceitos, ao descreverem que "na dengue hemorrágica, provocada por outro tipo de vírus [...]" (LINHARES; GEWANDSZNAJDER, 2005, p. 149). A febre dengue hemorrágica é o agravamento do quadro clínico da dengue, podendo, assim, estar associada a quaisquer dos sorotipos do vírus da dengue, e não a outro vírus, como destacam os autores. Ainda segundo a afirmativa dos autores, presume-se, de forma incorreta, que o vírus da dengue apresenta uma única variação. Como foi reportado anteriormente, a etiologia da doença pode ser atribuída a quatro sorotipos diferentes, e não apenas a uma variação (WORLD HEALTH ORGANIZATION, 2009). De modo geral, os livros didáticos não empregam explicações quanto à etiologia e potenciais vetores da dengue. Estes aspectos são, em sua maioria, apenas citados nos livros didáticos. O conteúdo é apresentado de forma excessivamente simplificada, resultando em tópicos pouco elucidativos e com conceitos científicos incorretos.

\section{Concepções sobre a transmissão}

Dentre o total de obras analisadas, $90 \%(\mathrm{n}=36)$ dos livros apontam a obrigatoriedade da presença de um vetor para que a transmissão da dengue ocorra. Tal indicativo é importante para a compreensão dos mecanismos envolvidos na transmissão da doença e, também, para a adoção de medidas de controle eficientes. No exemplar 6 do PNLD 2008, ocorre a associação da dengue com a leptospirose, cólera, meningite e febre amarela. A todas as doenças é atribuída a responsabilidade por surtos epidêmicos. No entanto, algumas dessas doenças, como a leptospirose, cólera e meningite, têm a propagação favorecida pela falta de higiene, tal como a contaminação da água após enchentes ou pelo despejo de esgotos. O Aedes aegypti, por sua vez, tem preferência em depositar seus ovos em ambiente com água relativamente limpa. Somente três livros (14; III e I) apresentaram o ciclo de transmissão da doença enfatizando a tríade vetores, humanos e reservatórios. No entanto, não são discutidos os múltiplos fatores que condicionam a presença e manutenção de potenciais criadouros do Aedes aegypti. Portanto, aproximadamente $93 \%$ das obras didáticas de ciências e biologia que contemplaram a temática da dengue negligenciam o aspecto referente ao ciclo de transmissão da doença, que é fundamental para a compreensão dos mecanismos de propagação do agravo e a adoção de ações de controle. 
A dengue nos livros didáticos ...

\section{Concepções sobre a prevenção e o controle}

Nos livros didáticos analisados, a configuração de uma ciência desvinculada da realidade esteve acentuadamente presente nos trechos voltados à prevenção e controle da dengue. No livro 3, é reportado que "as informações deste capítulo têm o objetivo de ajudar as pessoas a conhecer melhor as doenças relacionadas com os vírus, mas não substituem a consulta médica, nem podem ser usados para o diagnóstico, tratamento ou prevenção de doenças" (GEWANDSZNAJDER, 2006c, p. 62). Considera-se tal afirmação com relação à prevenção equivocada, pois um dos objetivos do PCN de ciências naturais é de que o conteúdo disciplinar seja vinculado à prática social do aluno, e que este seja capaz de incentivá-lo para ações condizentes com a preservação da saúde coletiva e individual. Compreende-se que não se deve realizar um diagnóstico e tratamento sem um acompanhamento médico, mas as medidas de prevenção podem e devem ser praticadas pela comunidade. Assim, é oportuno que o instrumento pedagógico empregado pelo professor ofereça o conhecimento necessário para que os indivíduos tornem-se conscientes dos aspectos preventivos das doenças e agravos que põem em risco a saúde. Frequentemente, o conhecimento científico é tratado como um fim em si mesmo, uma verdade absoluta, desvinculado do contexto histórico e sociocultural (MEGID NETO; FRACALANZA, 2003). Os exemplares 1, 2, 3 e 13, II, XII, XIII, G, H e I apontam, como medida prioritária para controle da dengue, a pulverização de inseticidas para eliminação de vetores. Entretanto, deve ser observado que modelos voltados à prevenção da dengue pautados essencialmente no combate químico do vetor são incapazes de obter sucesso (FERREIRA; VERAS; SILVA, 2009). A utilização destes produtos pode trazer risco à saúde ambiental, bem como o uso indiscriminado destes promove a seleção artificial de mosquitos, induzindo, assim, o aparecimento de populações resistentes (BRAGA; VALLE, 2007a). Em estudo realizado entre os anos de 1999 e 2000, verificou-se que, em municípios das regiões Nordeste e Sudeste, populações de Aedes aegypti eram resistentes aos inseticidas do tipo temephos (BRAGA; VALLE, 2007b). Devido a fatores políticos e econômicos, instituições governamentais tendem a supervalorizar o uso excessivo de inseticidas e utilizam-no como o seu principal meio de controle da doença. Medidas de prevenção e controle da dengue requerem a articulação de múltiplos aspectos, além da vigilância epidemiológica e controle vetorial; e devem incluir ações de educação em saúde com o objetivo de promover a mobilização popular, constituindo, assim, um pilar essencial para o enfrentamento da dengue (BRASIL, 2009). O emprego de adulticidas de forma indiscriminada gera uma falsa sensação de segurança na população, pois são eficientes apenas contra uma parcela da população do vetor. Como indica o Ministério da Saúde os inseticidas (adulticidas) devem ser utilizados apenas em situações extremas onde há risco iminente de epidemia (BRASIL, Ministério da Saúde, 2011; WORLD HEALTH ORGANIZATION, 2009). Deve-se pontuar, ainda, que este tipo de abordagem remete a concepções antropocêntricas em relação ao ambiente (AMARAL et al., 2006).

Nos exemplares 1, XII e G, é recomendado o uso de telas em portas e janelas a fim de se evitar o acesso do Aedes aegypti nas residências. Entretanto, não é indicado, nos exemplares, o tamanho do Aedes aegypti, de modo que a adoção de tal recurso pode ser inútil, já que, dependendo do diâmetro da tela, esta pode ser inadequada para promover a retenção do mosquito, como preveem os autores. A colocação de telas em portas e janelas é apontada como uma medida adequada pelo Ministério da Saúde (BRASIL, 2005). Contudo, deve-se considerar 
Assis, S. S.; Pimenta, D. N.; Schall, V. T.

a baixa eficiência desta ação, tendo em vista que parte dos criadouros em potencial ou infestados por ovos e formas imaturas do Aedes aegypti se encontram na região intradomiciliar (LENZI; COURA, 2004; LIMA-CAMARA; HONÓRIO; OLIVEIRA, 2006). Nas obras A e G, é indicada a troca frequente da água retida no interior de vasos de plantas, medida esta que não é totalmente eficiente, pois os ovos do Aedes aegypti podem permanecer fixados no interior destes recipientes, necessitando apenas que entrem em contato com a água para que eclodam. Na obra C, não é apresentado o ciclo de vida do Aedes aegypti e tampouco há explicação sobre a importância da água para eclosão dos ovos deste inseto, mas, ao final do texto, o autor enfatiza que, para a contenção do vetor, é necessário que não sejam deixados recipientes com água parada. Ou seja, a informação aparece descontextualizada e de modo prescritivo. O Ministério da Saúde indica a não-manutenção de plantas em recipientes com água e de pratos coletores em vasos de plantas ou xaxins. Caso se opte pela adoção de pratinhos, estes devem ser preenchidos de areia a fim de que se evite o acúmulo de água no seu interior e, consequentemente, um local propício para oviposição e desenvolvimento do Aedes aegypti (BRASIL, 2009). No entanto, Barros (2007) alerta que a adoção, no ambiente domiciliar, desta ação apresenta resistência, uma vez que o espalhamento da areia causa sujeira no interior das residências. A eficiência desta medida também é questionada; a não ser que haja troca constante da areia, a medida torna-se efetiva, pois, com o passar do tempo, há redução do volume, promovendo a formação de uma lâmina de água acima da camada de areia. Assim, somente a adoção de dispositivos capazes de vedar o recipiente ou a não- utilização destes é que evitará a ovipostura e desenvolvimento de larvas no recipiente (BARROS, 2007; SCHALL et al., 2009).

Os aspectos preventivos expressos nos LD de biologia e de ciências, de modo geral, remetem a um bloco de prescrições a serem seguidas, muitas das quais sem maior contextualização. Assim, o livro didático tem se limitado à reprodução do que é encontrado em boa parte dos processos educativos voltados à prevenção da dengue. Medidas preventivas da dengue frequentemente surgem como um conjunto de procedimentos técnicos a serem adotados sem que seja considerada a forma não linear entre o conhecer e o agir no qual os indivíduos pautam suas práticas (LENZI; COURA, 2004). A presença de informações desconexas e o apontamento de ações a serem adotadas sem que estas sejam esclarecidas tornam o conteúdo ineficiente para a prevenção de agravos, uma vez que o leitor não relaciona o conteúdo com o seu cotidiano e, consequentemente, não o coloca em prática. Remete-se à ideia de que o conteúdo científico presente nas obras didáticas é desvinculado da realidade da população à qual tais obras são destinadas. O livro enquanto recurso didático então deixa de exercer sua função social.

\section{Concepções sobre diagnóstico e tratamento}

Em geral, os livros didáticos não dedicam muito espaço às questões sobre o diagnóstico e tratamento da doença. Somente nos livros 11, 13, XI, XIII e C é empregado o alerta quanto à necessidade de acompanhamento médico em caso suspeito de dengue. Embora nem sempre a população possa contar com serviços públicos de saúde de qualidade, o tratamento da doença deve ser realizado pelo médico. Ou seja, o tratamento doméstico sem a indicação de um profissional qualificado pode convergir para quadros graves da doença e acarretar óbito. $\mathrm{O}$ autor do livro G indicado no catálogo do PNLEM 2009, ao descrever as medidas preventivas 
da dengue, aponta que "em caso de tratamento doméstico, manter o doente em recinto fechado, evitando o seu contato com os mosquitos Aedes, que podem picar e assim contaminar toda a família e vizinhos" (PAULINO, 2005, p. 31). Entretanto, esta informação pode conotar cunho preconceituoso, induzindo o afastamento dos indivíduos acometidos pela dengue do restante da população, o que não está presente no rol de medidas de controle da doença e dos seus vetores, uma vez que a transmissão da doença não se processa pessoa a pessoa, nem por meio de fluidos corporais, secreções orgânicas ou fomites, como indicado pelo Ministério da Saúde e a OMS (BRASIL, 2009; WORLD HEALTH ORGANIZATION, 2009). Com esta ausência de abordagem sobre o tema do diagnóstico e tratamento nas coleções indicadas nos catálogos do PNLD 2008 e 2011 e PNLEM 2009, constatamos que a dengue é banalizada, tratada de forma prescritiva e superficial. Portanto, segundo as concepções presentes em grande parte dos exemplares de ciências e biologia analisadas, torna-se dispensável o tratamento com acompanhamento médico, bem como a presença deste profissional para o diagnóstico.

\section{Linguagem}

Em geral, nos livros didáticos, a questão da linguagem é formulada de forma inadequada, pois os conceitos não são detalhados e são descritos com vocabulário que proporciona confusão na compreensão dos tópicos abordados. As medidas preventivas para a dengue, apontadas nos exemplares de ciências e biologia, fazem uso de vocabulário impróprio e de cunho sanitarista. O fato pode ser exemplificado através da afirmação presente na obra, destinada ao $2^{\circ}$ ano do Ensino Médio, de Silva Júnior e Sasson (2005b, p. 207), onde é apontado que "a única arma na luta contra a dengue é, portanto, a profilaxia, que consiste basicamente no extermínio do mosquito vetor, o $A$. aegypti [...]". A utilização deste vocabulário não é adequada, pois remete a um período ultrapassado da educação em saúde onde se utilizava palavras de cunho campanhista e de "guerra". Além do mais, o "extermínio" massivo do mosquito vetor, descrito pelo autor, envolveria a utilização expressiva de inseticidas que podem acarretar perigos à saúde ambiental e da população, fato este que não é ponderado no exemplar. Ainda em relação à linguagem dos aspectos preventivos, $45 \%(\mathrm{n}=18)$ dos exemplares de ciências e biologia analisados utilizam linguagem inapropriada ao referirem à expressão "tampar e cobrir caixas e reservatórios contendo água". Lenzi e Coura (2004) apontam que a utilização do verbo tampar e cobrir pode favorecer uma interpretação equivocada e, consequentemente, a adoção de práticas não apropriadas, na medida em que orifícios ou brechas podem ser mantidos, garantindo, assim, o acesso do vetor à região próxima a água, propícia para a deposição de seus ovos. Assim, o mais indicado seria a troca do verbo tampar ou cobrir, por vedar. Jardim e Schall (2009) ponderam que as indicações quanto aos cuidados com recipientes utilizados para armazenamento de água no ambiente doméstico devem utilizar linguagem objetiva em relação ao comportamento que se quer induzir; assim, os materiais educativos não devem privilegiar vocábulos vagos, ambíguos ou indefinidos. 
Assis, S. S.; Pimenta, D. N.; Schall, V. T.

\section{Ilustração ${ }^{6}$}

Foram identificadas 58 imagens relacionadas à dengue nos livros didáticos. A maior parte das ilustrações (53\%) refere-se ao vetor da dengue Aedes aegypti. Observou-senos livros indicados pelo PNLD/2008 e PNLEM/2009, a presença de imagens com ausência de escala e fonte. Já nas obras analisadas provenientes do PNLD/2011, esses itens estavam presentes, indicando uma relativa melhora das coleções didáticas neste sentido. A presença de escala nas ilustrações empregadas nos livros didáticos assegura o acesso do público escolar ao tamanho real do que é mostrado, no caso o vetor Aedes aegypti. Quando alunos e professores são privados desta informação, contribui-se para a formação de visões deturpadas em relação aos organismos vivos e seu reconhecimento na realidade.

Os livros 9,10, 14, V, X, XV e F contemplaram a reprodução de cartazes oriundos de campanhas voltadas à prevenção da dengue para ilustrar o vetor e/ou medidas de controle. Grande parte dos impressos empregados nas campanhas não considera o público-alvo e descreve as ações de prevenção e controle de forma prescritiva, sem qualquer estímulo à reflexão e participação em tais atividades. Assim, os aspectos referentes a especificidades culturais, cognitivas e sociais de cada grupo são negligenciados (NOGUEIRA; MODENA; SCHALL, 2009). Além do mais, é comum encontrar incorreções e inadequações nos materiais educativos/informativos impressos. As Figuras 1 e 2 são exemplos dos aspectos mencionados. $\mathrm{O}$ cartaz reproduzido na obra 14 (Figura 1) tem baixa qualidade gráfica, e os elementos relacionados aos estágios de vida do mosquito não contêm escala. Não há referência da imagem no corpo do texto, e a ilustração é ainda inadequada, pois possibilita a interpretação equivocada de que o desenvolvimento do ciclo do vetor se processa no dedo/mão do homem.

Outra questão recorrente nas ilustrações é a utilização de imagens grotescas ${ }^{7}$. Nos livros 3; XI e F, verificou-se a utilização de ilustrações caricatas do Aedes aegypti. Embora as caricaturas tenham o potencial de tratar o tema de forma mais lúdica, a sua utilização deve ser feita com cautela, pois podem contribuir para a construção de conceitos equivocados. Ademais, estas podem contrariar o preceito básico sobre a função das ilustrações nos materiais didáticos e educativos: colaborar para o entendimento do texto (ARAÚJO, 2006). Ao abordarem a necessidade da presença de um vetor para a disseminação de algumas doenças, os autores do livro F reproduzem um cartaz da campanha de prevenção da dengue (figura 2). A ilustração apresenta uma caricatura grotesca do Aedes aegypti, exagerando-se a representação do seu corpo de forma monstruosa, incluindo até "dentes" no vetor ${ }^{8}$. O vetor também é identificado, apenas, como mosquito da dengue, e não pelo seu nome científico.

\footnotetext{
${ }^{6}$ Devido à extensão desta temática, realizou-se uma análise das representações visuais da dengue em livros didáticos e em materiais educativos/informativos em outra publicação.

${ }^{7}$ Esses materiais seguem a tendência de utilização de imagens grotescas na área da saúde (PIMENTA; LEANDRO; SCHALL, 2007). Segundo Sodré e Paiva (2002), o grotesco caracteriza-se como uma categoria estética onde se privilegia uma mutação brusca ou uma valorização de uma forma onde o verdadeiro e o irreal são associados.

${ }^{8} \mathrm{O}$ Aedes aegypti realiza a sucção do sangue por meio da probóscide que compõe o seu aparelho bucal (CONSOLI; OLIVEIRA, 1994).
} 
A dengue nos livros didáticos ...

Figura 1. Representação inadequada do ciclo de vida do Aedes aegypti.

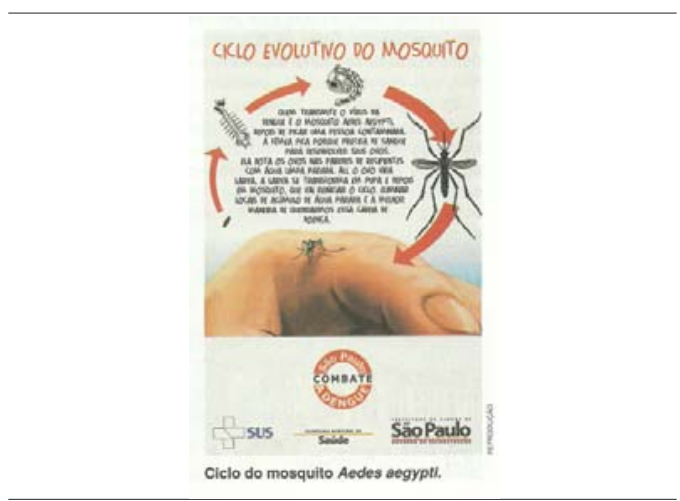

Fonte: Bortolozzo; Maluhy (2005, p. 149)
Figura 2. Representação caricatural e grotesca do Aedes aegypti.

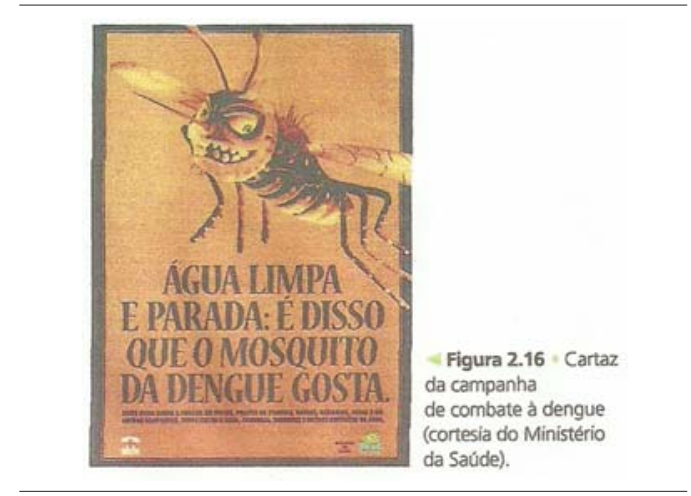

Fonte: Amabis; Martho (2004, p. 44).

\section{Considerações finais}

O conteúdo sobre dengue presente nos livros didáticos de ciências e biologia, quase sem exceção, apresentou tópicos idênticos, organizados em sequência bastante semelhante, utilizando ilustrações parecidas. Portanto, nossas constatações corroboram a descrição de Fracalanza (2006) de que as coleções didáticas sofrem nenhuma ou reduzidas alterações significativas em suas sucessivas edições, e acabam mantendo, entre si, excessiva padronização. Perpetuam visões distorcidas acerca da ciência, reproduzindo erros e inadequações acerca dos conteúdos e ilustrações veiculados neste material, o que repercute no saber docente e prejudica o processo de ensino-aprendizagem, como constatado por Assis, Pimenta e Schall (2013). A abordagem de aspectos que permitem a identificação do vetor e dos seus criadouros em potencial é imprescindível. Entre as coleções de ciências analisadas, os conteúdos referentes à dengue apresentaram maior disseminação nos livros indicados pelo PNLD 2011. Estas obras apresentaram, ainda, ilustrações mais correlatas ao texto, não sendo identificadas, dentre essas, ausência de escala ou fonte, representando, assim, uma melhora na qualidade da abordagem do tema em exemplares editados mais recentemente. Como verificado nas obras de ciências, estiveram presentes, nas coleções de biologia aprovadas pelo PNLEM 2009, erros conceituais e abordagem da temática de forma descontextualizada da prática social do público a que se destinam: alunos e professores. Foram exíguas, nos livros de ciências e biologia analisados, as informações em torno da transmissão, diagnóstico e tratamento, podendo acarretar uma menor compreensão, por parte dos docentes e discentes, dos aspectos envolvidos no processo saúde/ doença. Os livros, de modo geral, não explicitam a importância do estudo do tema, desfavorecendo a aprendizagem sobre os aspectos referentes à dengue. Deve-se considerar que:

O exame do livro didático não pode escapar ao exame da própria função da escola e de como ela vem sendo expressa [...] de uma forma ou de outra, toda análise ou crítica do livro didático deve supor a análise 
Assis, S. S.; Pimenta, D. N.; Schall, V. T.

ou crítica da própria escola e da filosofia a que pertence. Em última instância, uma análise ou crítica da própria sociedade. (OLIVEIRA; GUIMARÃES; BOMÉNY, 1984, p. 29)

Assim, partindo-se das inadequações apontadas nos livros didáticos de ciências e biologia em relação à dengue, deve-se repensar não somente a abordagem do tema no espaço de ensino formal, mas, também, os valores sociais e as representações de ciência sobre os quais a escola e sociedade estão alicerçadas. Muito mais do que oferecerem respaldo à prática docente, os livros didáticos indicados pelo PNLD e PNLEM têm potencial de mediar o saber de natureza científica para os alunos do Ensino Básico. Deste modo, é fundamental que este instrumento proporcione vinculação do conhecimento à prática social dos escolares. Concluise que os conhecimentos apresentados nos LD analisados se basearam, quase que unicamente, na emissão linear de informações a respeito da descrição patológica, e um conjunto de normas técnicas prescritivas a serem adotadas pela comunidade escolar, ignorando o desenvolvimento de conteúdos sobre processos e fatores condicionantes envolvidos na complexidade do agravo. Contrariam-se, assim, as recomendações do PCN e PCNEM. A análise da temática da dengue, em livros didáticos de ciências e biologia distribuídos às escolas públicas brasileiras a partir dos exemplares indicados nas edições de 2008, 2011 e 2009 do PNLD e PNLEM, respectivamente, revelam a manutenção de um padrão verificado por Mohr (1995), onde ao se abordar a saúde privilegiam-se indicativos pouco fundamentados de práticas higiênicas a serem adotadas. Este mesmo modelo de educação em saúde também foi identificado em livros didáticos de outros países, como França e Itália, analisados entre os anos de 2005 e 2006 (CARVALHO et al., 2008). Portanto, a valorização da abordagem do processo saúde-doença em uma perspectiva biomédica e higienista não são exclusivas em relação à temática da dengue, sendo esta forma um traço marcante quanto à abordagem, em livros didáticos, dos temas relacionados aos agravos à saúde. Este padrão precisa ser superado para que se possibilite que a saúde seja percebida de forma mais integrada. Avaliações realizadas pelo PNLD e pelo PNLEM são imprescindíveis para que seja assegurada a qualidade das obras didáticas. Assim, sugere-se, fortemente, que sejam aperfeiçoados os critérios de análise das coleções didáticas de ciências e biologia, a fim de que estas se tornem uma ferramenta realmente eficaz para proporcionar, aos indivíduos, uma perspectiva de ciência mais ampla, voltada à promoção da saúde e ao exercício consciente da prática social, associada à apropriação cientificamente correta do saber relacionado aos processos de saúde/doença, deixando de ser uma lacuna ou um entrave ao aprendizado dos alunos e ao exercício docente. 
A dengue nos livros didáticos ...

\section{Referências}

ADOLFO, A; CROZETTA, M.; LAGO, S. Biologia: volume único: ensino médio. 2. ed. São Paulo: IBEP: 2005.

ALBUQUERQUE, K. M. História e crítica do modelo clássico: perspectiva ecossistêmica. In: AUGUSTO, L. G. S.; CARNEIRO, R. M.; MARTINS, P. H. (Org.). Abordagem ecossistêmica em saúde: ensaios para o controle de dengue. Recife: Editora Universitária da UFPE, 2005. p. 101-105.

ALMEIDA, A. V.; SILVA, L. S. T.; BRITO, R. L. Desenvolvimento do conteúdo sobre os insetos nos livros didáticos de ciências. Revista Brasileira de Pesquisa em Educação em Ciências, Belo Horizonte, v. 8, n. 1, p. 1-17, 2008.

AMABIS, J. M.; MARTHO, G. R. Biologia dos organismos $-2^{a}$ série. 2. ed. São Paulo: Moderna, 2004.

AMARAL, I. A. et al. Avaliando livros didáticos de ciências: análise das coleções didáticas de ciências de $5^{a}$ a $8^{a}$ séries do ensino fundamental. In: MEGID NETO, J.;

FRACALANZA, H. (Org.). O livro didático de ciências no Brasil. Campinas: Komedi, 2006. p. 197-216.

ANGELO, E.; SILVA, K.; FAVALLI, L. Projeto Radix: ciências - $6^{\circ}$ ano. São Paulo: Scipione, 2009a.

Projeto Radix: ciências $-7^{\circ}$ ano. São Paulo: Scipione, 2009b.

ARAÚJO, E. Materiais educativos e produção de sentidos na intervenção social. In: MONTEIRO, S.; VARGAS, E. (Org.). Educação, comunicação e tecnologia

educacional: interfaces com o campo da saúde. Rio de Janeiro: Fiocruz, 2006. p. 49 - 69.

ASSIS, S. S.; PIMENTA, D. N.; SCHALL, V. T. Conhecimentos e práticas educativas sobre dengue: a perspectiva de professores e profissionais de saúde. Ensaio: Pesquisa em educação em ciências, Belo Horizonte, v. 15, n. 1, p. 131-153, 2013.

BARRETO, L. B.; TEIXEIRA, M. G. Dengue no Brasil: situação epidemiológica e contribuições para uma agenda de pesquisa. Estudos Avançados, São Paulo, v. 22, n. 64, p. 53-72, 2008.

BARROS, C.; PAULINO, W. R. Ciências: os seres vivos - $\sigma^{a}$ série. Edição reformulada. São Paulo: Ática, 2006.

Ciências: os seres vivos $-6^{\circ}$ ano. 4. ed. São Paulo: Ática, 2009.

BARROS, H. S. Investigação de conhecimentos sobre a dengue e do índice de adoção de um recurso preventivo (capa evidengue ${ }^{\circledR}$ ) no domicílio de estudantes, associados a uma ação educativa em ambiente escolar. 2007. 118 f. Dissertação (Mestrado em Ensino em Biociências e Saúde) - Instituto Oswaldo Cruz, Fundação Oswaldo Cruz, Rio de Janeiro, 2007. 
Assis, S. S.; Pimenta, D. N.; Schall, V. T.

BARZANO, M. A. L. Saneamento básico, história da ciência e formação de professores: um relato de experiência. In: TEIXEIRA, P. M. M.; RAZERA, J. C. C. (Org.). Ensino de ciências: pesquisas e pontos em discussão. Campinas: Komedi, 2009. p. 251-270.

BATISTA, M. V. A.; CUNHA, M. S.; CÂNDIDO, A. L. Análise do tema virologia em livros didáticos do ensino médio. Ensaio: Pesquisa em educação em ciências, Belo Horizonte, v. 12, n. 1, p. 1-18, 2010.

BIZZO, N.; JORDÃO, M. Ciências BJ: 6a série. 2. ed. São Paulo: Editora do Brasil, 2006.

Ciências BJ: $7^{\circ}$ ano. São Paulo: Editora do Brasil, 2009.

BORTOLOZZO, S.; MALUHY, S. Série link da ciência: ciências, $6^{a}$ série: livro do professor. 2. ed. São Paulo: Escala Educacional, 2005.

BRAGA, I. A.; VALLE, D. Aedes aegypti: surveillance, resistance monitoring, and control alternatives in Brazil. Revista de Epidemiologia e Serviços de Saúde, Brasília, v. 16, n. 4, p. 295-302, 2007a.

Aedes aegypti: histórico do controle no Brasil. Revista de Epidemiologia e

Serviços de Saúde, Brasília, v. 16, n. 2, p. 113-118, 2007 b.

BRAGA, S. A. M. et al. Construindo consciências: ciências, $5^{a}$ série. Apec - Ação e Pesquisa em Educação em Ciências. São Paulo: Scipione, 2006.

. Construindo consciências: $6^{\circ}$ ano. São Paulo: Scipione, 2009a.

. Construindo consciências: $9^{\circ}$ ano. São Paulo: Scipione, 2009b.

BRASIL. Ministério da Educação. Biologia: catálogo do Programa Nacional do Livro para o ensino médio: PNLEM/2009. Brasília, 2008.

Parâmetros curriculares nacionais: ciências naturais - terceiro e quarto ciclos do ensino fundamental. Brasília, 1998.

. Fundo Nacional de Desenvolvimento da Educação. Resolução No 002 de 03 de abril de 2007. Brasília, 2007a.

Guia de livros didáticos: PNLD 2008: ciências. Brasília, 2007b.

Guia de livros didáticos: PNLD 2011: ciências. Brasília, 2010.

Guia de livros didáticos: PNLD 2012: apresentação. Brasília, 2011.

. Ministério da Educação e do Desporto. Secretaria de Educação Média e

Tecnológica. Parâmetros curriculares nacionais ensino médio: ciências da natureza, matemática e suas tecnologias. Brasília, 1999. v. 3.

. Ministério da Educação e do Desporto. Fundo Nacional de Desenvolvimento da Educação. Resolução No 38 de 15 de outubro de 2003. Brasília, 2003.

Ministério da Saúde. Diretrizes nacionais para a prevenção e controle de epidemias de dengue. Brasília, 2009. (Série A: normas e manuais técnicos). 
A dengue nos livros didáticos ...

Guia de vigilância epidemiológica. 6. ed. Brasília, 2005. (Série A: normas e manuais técnicos).

Ministério da Saúde. Coordenação Geral do Programa Nacional de Controle da Dengue. Casos de Dengue. Brasil, Grandes Regiões e Unidades Federadas. 1997 a 2011. Brasília, 2012. Disponível em: < http://portal.saude.gov.br/portal/arquivos/pdf/ dengue_classica_90_11_10_02_12.pdf $>$. Acesso em: 13 maio 2012.

Ministério da Saúde. Secretaria de Vigilância em Saúde. Nota técnica N. ${ }^{\circ} 216$ / 2011 CGPNCD/DEVIT/SVS/MS: estratégias de controle da dengue do município de Foz de Iguaçu/PR. Brasília, 2011. Disponível em: <http://portal.saude.gov.br/portal/ arquivos/pdf/nt_foz_de_iguacu_revsiada_jb.pdf>. Acesso em: 14 dez. 2011.

BRÜGGER, P. Educação ou adestramento ambiental? 3. ed. Florianópolis: Letras Contemporâneas, 2004.

CANTO, E. D. Ciências naturais: aprendendo com o cotidiano - $5^{\text {a }}$ série. 2. ed. São Paulo: Moderna, 2004a.

Ciências naturais: aprendendo com o cotidiano $-6^{a}$ série. 2. ed. São Paulo: Moderna, 2004b.

Ciências naturais: aprendendo com o cotidiano $-6^{\circ}$ ano. 3. ed. São Paulo: Moderna, 2009a.

Ciências naturais: aprendendo com o cotidiano $-7^{\circ}$ ano. 3. ed. São Paulo: Moderna, 2009b.

CARLINI-COTRIM, B.; ROSEMBERG, F. Os livros didáticos e o ensino para a saúde: o caso das drogas psicotrópicas. Revista de Saúde Pública, São Paulo, v. 25, n. 4, p. 299-305, 1991.

CARVALHO, G. S. et al. Comparing health education approaches in textbooks of sixteen countries. Science Education International, Hatfield, v. 19, n. 2, p. 133-146, 2008.

Disponível em: <http:// repositorium.sdum.uminho.pt/bitstream/1822/8237/1/

Health\%20Ed.pdf >. Acesso em: 7 dez. 2011.

CONSOLI, R. A. G. B.; OLIVEIRA, R. O. Principais mosquitos de importância sanitária no Brasil. Rio de Janeiro: Editora Fiocruz, 1994.

COSTA, A. Ciências e interação: $6^{a}$ série. Curitiba: Positivo, 2006.

CRUZ, J. L. C. (Ed.). Projeto Arirabá: ciências - 6a série. São Paulo: Moderna, 2006.

FAVARETTO, J.A; MERCADANTE, C. Biologia: volume único. São Paulo: Moderna, 2005.

FERREIRA, A. M.; SOARES, C. A. A. A. Aracnídeos peçonhentos: análise das informações nos livros didáticos de ciências. Ciência e Educação, Bauru, v. 14, n. 2, p. 307-314, 2008. 
Assis, S. S.; Pimenta, D. N.; Schall, V. T.

FERREIRA, I. T. R. N.; VERAS, M. A. S. M.; SILVA, R. A. Community participation in dengue control: an analysis of the sensitivity of municipal health plans in the State of São Paulo, Brazil. Cadernos de Saúde Pública, Rio de Janeiro, v. 25, n. 12, p. 2683-2694, 2009.

FIGUEIREDO, M. T.; CONDEIXA, C. G. Ciências: atitude e conhecimento - $6^{\circ}$ ano. São Paulo: FTD, 2009a.

Ciências: atitude e conhecimento $-7^{\circ}$ ano. São Paulo: FTD, 2009b.

Ciências: atitude e conhecimento $-9^{\circ}$ ano. São Paulo: FTD, 2009c.

FRACALANZA, H. Livro didático de ciências: novas ou velhas perspectivas. In:

FRACALANZA, H.; MEGID NETO, J. (Org.). O livro didático de ciências no Brasil. Campinas: Komedi, 2006. p. 173-195.

FRACALANZA, H.; MEGID NETO, J. Livro didático de ciências no Brasil: a pesquisa e o contexto. In: . (Org.). O livro didático de ciências no Brasil. Campinas: Komedi, 2006. p. 9-16.

FREITAG, B.; COSTA, W. F.; MOTTA, V. R. O livro didático em questão. 3. ed. São Paulo: Cortez, 1997.

FROTA-PESSOA, O. Biologia - 2 a série. São Paulo: Scipione, 2005.

GEWANDSZNAJDER, F. Ciências: a vida na Terra - 6ª série. São Paulo: Ática, $2006 a$.

Ciências: o planeta Terra $-6^{\circ}$ ano. São Paulo: Ática, 2006b.

Ciências: a vida na Terra $-7^{\circ}$ ano. 4. ed. São Paulo: Ática, 2006c.

Ciências: o planeta Terra $-6^{\circ}$ ano. 4. ed. São Paulo: Ática, 2009.

GOWDAK, D.; MARTINS, E. Ciências: novo pensar - $5^{a}$ série. 2. ed. renov. São Paulo: FTD, 2006a.

Ciências: novo pensar - $7^{\mathrm{a}}$ série. 2. ed. renov. São Paulo: FTD, 2006b.

HERMANSON, A. P.; JAKIEVICIUS, M. Investigando a natureza: ciências para o ensino fundamental - $8^{a}$ série. São Paulo: IBEP, 2006.

HERZLICH, C. Saúde e doença no início do século XXI: entre a experiência privada e a esfera pública. Physis: Revista de Saúde Coletiva, Rio de Janeiro, v. 14, n. 2, p. 383-394, 2004.

HÖFFLING, E. M. A trajetória do programa Nacional do Livro Didático do Ministério da Educação no Brasil. In: MEGID NETO, J.; FRACALANZA, H. (Org.). O livro didático de Ciências no Brasil. Campinas: Komedi, 2006. p. 19-31.

JARDIM, J. B.; SCHALL, V. T. Dengue prevention: focus on proficiency. Cadernos de Saúde Pública, Rio de Janeiro, v. 25, n. 11, p. 2529-2530, 2009.

LAURENCE, J. Biologia: ensino médio - volume único. São Paulo: Nova Geração, 2005. 
A dengue nos livros didáticos ...

LEÃO, F. B. F.; MEGID NETO, J. Avaliações oficiais sobre o livro didático de ciências. In: MEGID NETO, J. ; FRACALANZA, H. (Org.). O livro didático de ciências no Brasil. Campinas: Komedi, 2006. p. 33-80.

LENZI, M. F.; COURA, L. C. Prevenção da dengue: a informação em foco. Revista da Sociedade Brasileira de Medicina Tropical, São Paulo, v. 37, n. 4, p. 343-350, 2004.

LIMA-CAMARA, T. N.; HONÓRIO, N. A.; OLIVEIRA, R. L. Frequency and spatial distribution of Aedes aegypti and Aedes albopictus (Diptera, Culicidae) in Rio de Janeiro, Brazil. Cadernos de Saúde Pública, Rio de Janeiro, v. 22, n. 10, p. 2079-2084, 2006.

LINHARES, S.; GEWANDSZNAJDER, F. Biologia - volume único. São Paulo: Ática, 2005.

LOPES, S; ROSSO, S. Biologia - volume único. São Paulo: Saraiva, 2005.

LUZ, Z. M. P. et al. Evaluation of informative materials on leishmaniasis distributed in Brazil: criteria and basis for the production and improvement of health education materials. Cadernos de Saúde Pública, Rio de Janeiro, v. 19, n. 2, p. 561-569, 2003.

MACHADO, J. P.; OLIVEIRA, R. M.; SOUZA-SANTOS, R. Spatial analysis of dengue occurrence and living conditions in Nova Iguaçu, Rio de Janeiro State, Brazil. Cadernos de Saúde Pública, Rio de Janeiro, v. 25, n. 5, p. 1025-1034, 2009.

MEGID NETO, F;; FRACALANZA, H. O livro didático de ciências: problemas e soluções. Ciência \& Educação, Bauru, v. 9, n. 2, p. 147-157, 2003.

MOHR, A. A saúde na escola: análise de livros didáticos de $1^{\mathrm{a}}$ a $4^{\mathrm{a}}$ séries. Cadernos de Pesquisa, São Paulo, n. 94, p. 50-57, 1995.

Análise do conteúdo de saúde em livros didáticos. Ciência \& Educação, Bauru, v. 6, n. 2, p. 89-106, 2000.

MOLINA, O. Quem engana quem?: professor X livro didático. 2. ed. Campinas: Papirus, 1988.

NOGUEIRA, M. J. ; MODENA, C. M.; SCHALL, V. T. Materiais educativos impressos sobre saúde sexual e reprodutiva utilizados na atenção básica em Belo Horizonte, MG: caracterização e algumas considerações. Revista Eletrônica de Comunicação, Informação e Inovação em Saúde, Rio de Janeiro, v. 3, n. 4, p. 169-179, 2009. Disponível em: < http://www.reciis.cict.fiocruz.br/index.php/reciis/article/view/149/359>. Acesso em: 3 ago. 2010.

OliveirA, J. B. A.; GUIMARÃES, S. D. P.; BOMÉNY, H. M. B. A política do livro didático. São Paulo: Summus, 1984.

PAULINO, W. R. Biologia: seres vivos e fisiologia - 2a série. São Paulo: Ática, 2005.

PEREIRA, A. M. et al. Perspectiva ciências $-7^{\circ}$ ano. São Paulo: Editora do Brasil, 2009.

PIMENTA, D. N.; LEANDRO, A.; SCHALL, V. T. A estética do grotesco e a produção audiovisual para a educação em saúde: segregação ou empatia? O caso das leishmanioses no Brasil. Cadernos de Saúde Pública, Rio de Janeiro, v. 23, n. 5, p. 1161-1171, 2007. 
Assis, S. S.; Pimenta, D. N.; Schall, V. T.

REIS, D. C. Educação em saúde: aspectos históricos e conceituais. In: GAZZINELLI, M. F; MARQUES, R. C. (Org.). Educação em saúde: teoria, método e imaginação. Belo Horizonte: UFMG, 2006. p. 19-24.

SANTANA, O.; FONSECA, A.; MOZENA, E. Ciências naturais - $6^{\circ}$ ano. 3. ed. São Paulo: Saraiva, 2009.

SANTOS, J. C. et al. Análise comparativa do conteúdo Filo Mollusca em livro didático e apostilas do ensino médio de cascavel, paraná. Ciência e Educação, Bauru, v. 13, n. 3, p. 311-322, 2007.

SANTOS, R. C. Updating of the distribution of Aedes albopictus in Brazil (1997-2002).

Revista de Saúde Pública, São Paulo, v. 37, n. 5, p. 671-673, 2003.

SANTOS, V. C.; EL-HANI, C. N. Idéias sobre genes em livros didáticos de biologia do ensino médio publicados no Brasil. Revista Brasileira de Pesquisa em Educação em Ciências, Belo Horizonte, v. 9, n. 1, p. 1-23, 2009.

SCHALL, V. T. et al. Prevenção domiciliar da dengue: avaliação preliminar de tela protetora para pratos de vasos de planta. Revista de Saúde Pública, São Paulo, v. 43, n. 5, p. 895$897,2009$.

SCHALL, V. T. Saúde \& cidadania. In: PAVÃO, A. C. Ciências: ensino fundamental. Brasília: Secretaria de Educação Básica, 2010. (Coleção Explorando o Ensino, 18). p. 179-196.

SILVA JÚNIOR, C.; SASSON, S. Seres vivos: as características da vida, biologia celular, vírus: entre moléculas e células, a origem da vida e histologia animal - $1^{a}$ série. 8. ed. São Paulo: Saraiva, 2005a.

Seres vivos: estrutura e função - $2^{a}$ série. 8. ed. São Paulo: Saraiva, 2005b.

SILVA, S. N.; SOUZA, M. L.; DUARTE, A. C. S. O professor de ciências e sua relação com o livro didático. In: TEIXEIRA, P. M. M.; RAZERA, J. C. C. (Org.). Ensino de ciências: pesquisas e pontos em discussão. Campinas: Komedi, 2009. p. 147-166.

SODRÉ, M.; PAIVA, R. O império do grotesco. Rio de Janeiro: Mauad, 2002.

TRIVELLATO et al. Ciências, natureza \& cotidiano - 6 a série. São Paulo: FTD, 2006.

TRIVELLATO JÚNIOR, J. et al. Ciências, natureza $\boldsymbol{\&}$ cotidiano $-7^{\circ}$ ano. São Paulo: FTD, 2009.

VASCONCELOS, S. D.; SOUTO, E. O livro didático de ciências no ensino fundamental proposta de critérios para análise do conteúdo zoológico. Ciência e Educação, Bauru, v. 9, n. 1, p. 93-104, 2003.

WORLD HEALTH ORGANIZATION. Dengue: guidelines for diagnosis, treatment, prevention and control. Geneva: WHO, 2009.

Artigo recebido em 12/10/12. Aceito em 27/03/13.

656

Ciênc. Educ., Bauru, v. 19, n. 3, p. 633-656, 2013 